\title{
ERRATA
}

\section{Immunotherapy of Cancer with Nonliving BCG and Fractions Derived from Mycobacteria: Role of Cord Factor (Trehalose-6,6'-Dimycolate) in Tumor Regression}

A. BEKIERKUNST, L. WANG, R. TOUBIANA, AND E. LEDERER

Frederick Cancer Research Center, Frederick, Maryland 21701; Laboratory of Medical Bacteriology, The Hebrew University-Hadassah Medical School, Jerusalem, Israel; and Institut de Chimie des Substances Naturelles, Gif sur Yvette, France

Volume 10, no. 5, p. 1046, column 1, line 26: Delete the words "the following."

Page 1048, column 1, line 29: Change "treating" to "creating."

\section{Immunoelectron Microscopic Identification and Localization of Streptococcus sanguis with Peroxidase-Labeled Antibody: Localization of Surface Antigens in Pure Culture}

\author{
CHERN-HSIUNG LAI, MAX A. LISTGARTEN, AND BURTON ROSAN \\ Center for Oral Health Research and School of Dental Medicine, University of Pennsylvania, Philadelphia, \\ Pennsylvania 19104
}

Volume 11, no. 1, p. 193, column 2, lines 8-13: Delete sentence beginning "Cultures of $A$. viscosus ..."

Page 198, Table 1, column 2, last line, change "10048" to read "ATCC 10048." Column 3, add footnote $b$ to last four lines, to read "No reaction"." In footnote $b$, change "not" to read "nor."

Running head, change "Listgarden" to read "Listgarten." 